\title{
Comentários - Uma Apreciação sobre o Desenvolvimento dos Estudos em Estratégia no Brasil sob a Inspiração de Hafsi e Martinet
}

An Overview of the Development of Studies in Strategy in Brazil Inspired by Hafsi and Martinet

Luiz Paulo Bignetti * Ph.D. em Administração pela École des Hautes Études Commerciales (HEC) de Montreal, Canadá. Professor do PPGA/UNISINOS, São Leopoldo/RS, Brasil.

*Endereço: Avenida Unisinos, 950, São Leopoldo/RS, 93022-000. E-mail: bignetti@unisinos.br 
A análise de Hafsi e Martinet sobre a evolução do domínio da estratégia se desvincula das apreciações tradicionais por sua visão histórica, integradora e crítica. Os autores seguramente despontam como os mais expressivos pesquisadores adeptos da escola francófona do management stratégique e representam uma forte tradição no ensino e na pesquisa de estratégia na França e no Canadá. A publicação pela RAC do artigo mais recente desses autores enseja a oportunidade para uma reflexão alternativa sobre a teoria e a prática no campo da estratégia, cujo desenvolvimento quase sempre foi vinculado a uma linhagem anglosaxônica.

Partindo da análise histórica dos estudos sobre estratégia - o que faz lembrar as aulas extremamente interessantes e de grande conteúdo do Professor Hafsi o artigo desemboca em algumas questões essenciais. Por exemplo, tendo em vista os cerca de cinqüenta anos de desenvolvimento, de que forma o campo está hoje (des)estruturado? Em outras palavras, continua-se a encarar a estratégia como um bastão de cego, tateando-se teorias e práticas, num processo de tentativa e erro, em círculos, e sem direcionamento firme e qualificado? Ou há um punhado de conceitos convergentes e associados e um crescimento acentuado dos conhecimentos?

Evidentemente, é possível proceder a uma análise do desenvolvimento da estratégia das organizações e mostrar os ciclos, os períodos e as modas que surgiram ao longo do tempo. Hafsi e Martinet, no artigo em discussão, percorrem a trajetória e traçam essa evolução, atendo-se especialmente ao papel desempenhado pelos precursores da Harvard Business School e pelos modelos de Andrews e Ansoff. Encerram a avaliação histórica discutindo as dificuldades da aplicação dos estudos sobre estratégia e o fracasso da ciência em face da prática da gestão.

Antes deles, Allouche e Schmidt (1995) descreveram, em capítulos, as diferentes fases desse percurso: dos pioneiros ao triunfo do academicismo (até os anos 60); a erupção das empresas de consultoria e o triunfo das matrizes (durante os anos 60); a análise da concorrência e a exacerbação da competição (anos 70); a fascinação pelo modelo japonês e pela tecnologia (início dos anos 80); o reino efêmero dos gurus e da gestão de recursos humanos (final dos anos 80); e a gestão da crise e o resistível retorno da razão (final do século). Atualmente, talvez, uma nova fase esteja em curso: a influência da complexidade e a redução do horizonte temporal.

Allouche e Schmidt (1995) consideram ainda que as primeiras décadas do 
desenvolvimento dos estudos em estratégia se caracterizaram pela supremacia de um modelo racional, enquanto as duas últimas presenciaram o surgimento do irracional ou de um excesso de paixão. Citam, ainda, um dos autores do artigo em discussão, Alain-Charles Martinet, que afirma estar hoje presente um "componente nevrálgico do discurso sobre a estratégia" (Martinet como citado em Allouche \& Schmidt, 1995, p. 3) que, segundo eles, surge da turbulência (da economia mundial), da novidade (da inovação e da tecnologia), da complexidade (do número de variáveis pertinentes que cresce mais rápido que a capacidade de tratamento da informação) e da angústia (ou seja, da perda de sentido das sociedades industriais que se amplifica com a redução da previsibilidade). O próprio Martinet (2001), ao descrever o desenvolvimento da estratégia, constata o seu afastamento dos esforços de síntese. Propugna por uma inflexão dos estudos no sentido da busca por práticas de in-disciplina, pelo retorno ao terreno e pela retomada de uma perspectiva holística.

De qualquer forma que a evolução seja considerada, o campo da estratégia seja nos seus domínios da organização, seja na academia - findou por apresentar, segundo Hafsi e Martinet, algumas dicotomias ou tensões: a simplificação que contrasta com a complexidade, a objetivação e a especialização que limitam a compreensão do todo, a obsessão por resultados financeiros que impede a reflexão, o domínio cartesiano que elimina a integração, a retórica que substitui a ação e, finalmente, a transformação da estratégia puramente em técnicas que dispensam a ciência. Há, assim, um distanciamento entre academia e organização, entre teoria e prática.

Na organização, a pressão por resultados, advinda da necessidade de lucros crescentes e de retornos consideráveis aos acionistas, conduz os tomadores de decisão a optarem por medidas de curto prazo e por técnicas afastadas de uma formulação teórica adequada. A estratégia se distancia de uma perspectiva de longo prazo, de uma visão integradora, e se torna um conjunto de atividades baseadas em tentativa e erro. A retórica tende a substituir a reflexão, o discurso tenta explicar o erro. Ademais, os fins acabam por justificar os meios e as estratégias empregadas podem pender para um imediatismo, como dizem os autores, amoral: “ $\ldots$ os dirigentes abdicam de suas responsabilidades e se transformam em agentes obedientes que colocam em aplicação normas gerais de rentabilidade geralmente em detrimento da saúde a longo prazo da empresa e do simples bom senso".

Se a questão se volta para a academia e, especialmente, para os estudos sobre estratégia, não seria a situação análoga? Os acadêmicos não estariam 
acometidos dos mesmos males atribuídos aos executivos? Não estaria o campo sendo povoado por teorias ad hoc, por febres passageiras, por estudos superficiais? Não seriam os pesquisadores também reféns de uma pressão por resultados, advinda de um sistema que valoriza a produção numérica e desconsidera a qualidade? Não estariam eles comprometidos com o curto prazo - o próximo artigo - e não com uma linha coerente de pesquisa, com o aprofundamento dos estudos e com o avanço do conhecimento? Parafraseando os autores: "Estariam os pesquisadores abdicando de suas responsabilidades e transformando-se em agentes obedientes que colocam em aplicação normas gerais de produção científica geralmente em detrimento da saúde de longo prazo da ciência e do simples bom senso?". Estariam pesquisadores e executivos no mesmo barco e sem controlar o timão? O artigo de Hafsi e Martinet possibilita que se abra uma discussão sobre os estudos de estratégia e que se aborde, primordialmente, a situação da pesquisa no Brasil.

No que se refere à consistência teórica do campo, uma análise dos trabalhos publicados nos últimos dez anos no Brasil (Bignetti, Cappra, \& Thomas, 2007; Bignetti \& Paiva, 2002) não mostra, pelo menos em nível conceitual, uma diversificação acentuada de teorias. As cinco vertentes ressaltadas por Hafsi e Martinet - a economia industrial, a visão baseada em recursos, as teorias organizacionais, o institucionalismo e o empreendedorismo - podem também ser consideradas como as mais relevantes. Abordam-se aqui, particularmente, as quatro primeiras.

O predomínio da economia industrial tem-se mantido por longo tempo na análise estratégica. De fato, durante a conferência da Association Internationale de Management Stratégique, AIMS, de 1995, em Montreal, Richard Déry, colega de Taïeb Hafsi, já apresentava um trabalho sobre a estruturação do campo da estratégia, indicando que Porter era o autor da obra mais citada no Strategic Management Journal, com o seu já clássico Estratégia Competitiva. Desde aquela época, a predominância de Porter tem-se mantido, e seus conceitos são utilizados primordialmente na formulação e na postura estratégicas. No Brasil, em dez anos de acompanhamento, Porter continua sistematicamente à frente dos demais referenciados.

Atualmente, há uma crescente aplicação dos conceitos emanados pela Visão Baseada em Recursos (VBR), evidenciada pelo número de citações de autores que abraçam essa corrente (Hamel, Prahalad, Wernerfeldt, Barney, Grant, entre outros). Ao concentrar-se nas competências internas, a VBR traz em seu bojo algumas teorias organizacionais no desafio de entender como os recursos podem ser mobilizados para gerar maior competitividade. Há, 
entretanto, um nó ainda não totalmente desfeito: de que forma alinhar competências individuais e competências organizacionais? A clivagem entre ambas parece ser um obstáculo - e grande desafio - para a vinculação entre estratégia e estudos organizacionais.

Também o novo institucionalismo tem encontrado abrigo nos estudos de estratégia e duas alternativas teóricas se apresentam para as pesquisas sobre institucionalização: considerar o contexto como instituição ou considerar a organização como instituição (Zucker, 1987). No primeiro caso, os processos de institucionalização se vinculam ao poder coercitivo da sociedade e do Estado, que formam o contexto institucional, favorecendo o isomorfismo (DiMaggio \& Powel, 1991). No segundo caso, a institucionalização se desdobra através dos grupos intra-organizacionais e dos processos internos que formam o campo organizacional. Tolbert e Zucker (1999, pp. 206-210) descrevem os processos inerentes à institucionalização de práticas e comportamentos como um conjunto seqüencial de habitualização, objetificação e sedimentação.

Uma análise dos aportes teóricos trazidos para os estudos estratégicos, portanto, tende a indicar basicamente dois caminhos ou duas formas distintas de abordagem. De um lado, levando em conta a existência de uma interação ambiente-organização, a economia industrial e o institucionalismo, em sua concepção macro, são as alternativas teóricas mais prováveis. De outro, numa abordagem mais interna à organização, se entrelaçam a VBR, o neoinstitucionalismo, em sua concepção micro, e os estudos organizacionais sobre estrutura, processo, mudança, cultura e inovação. Mesmo assim, especialmente quando se procura entender a estratégia como processo, como a expressão de comunidade de pessoas ou como fio condutor (Hafsi \& Toulouse, 1996), algumas lacunas teóricas ainda restam e talvez possam ser preenchidas, especialmente por meio de contribuições advindas principalmente das ciências sociais e das ciências humanas. O potencial de desenvolvimento dos estudos sobre estratégia pode encontrar-se, justamente, nas possíveis conciliações entre concepções teóricas distintas e entre as duas formas de abordagem.

Os estudos sobre estratégia no Brasil, excetuada a presença e os trabalhos de alguns expoentes acadêmicos, ainda é campo em formação, mas que atrai cada ano novos adeptos: nos eventos promovidos pela ANPAD em 2007 mais de mil trabalhos foram submetidos à avaliação nos dois encontros realizados. Esse fluxo é, em grande parte, conseqüência da expansão da pós-graduação; a tendência é que o número de pesquisadores continue aumentando nos próximos anos. Tendo em vista, portanto, os aprofundamentos teóricos ainda possíveis e o crescimento no número de pesquisadores, os estudos de estratégia no Brasil tendem a se 
intensificar. No entanto, aproveitando as provocações trazidas por Hafsi e Martinet, este parece ser o momento para que dois aspectos sejam ressaltados, servindo como pano de fundo para uma discussão mais aprofundada.

Em primeiro lugar, apesar das convergências teóricas apontadas anteriormente, o que se observa através dos trabalhos publicados no Brasil é uma dominação anglo-saxônica evidente e a inexistência de um corpo teórico consistente e contextualizado que conduza a uma orientação (ou escola) brasileira de estratégia. Como resultado, a aplicação de modelos exógenos afasta a academia da realidade das empresas e separa, cada vez mais, a teoria da prática. O discurso se volta principalmente para o encantamento representado pelas grandes corporações e esquece a realidade de milhares de pequenas e médias empresas que se defrontam com desafios globais.

Em segundo lugar, e aqui reside o ponto essencial para discussão, a forte regulação a que estão submetidos os programas de pós-graduação - e os pesquisadores a eles vinculados - pode representar uma ameaça ao avanço dos conhecimentos e ao desenvolvimento de uma forte base conceitual em estratégia. Assim como, segundo Hafsi e Martinet, os tomadores de decisão estão comprometidos com resultados financeiros e submetidos a uma lógica de maximização, os acadêmicos estão permanentemente pressionados a publicar artigos e são avaliados por critérios unicamente quantitativos. O funcionamento dos programas de pós-graduação é regulado por normas de excelência: composição do corpo docente, número de publicações por docente, produção discente, número de orientandos por docente, tempo médio de duração de mestrados e doutorados etc. Valoriza-se, assim, cada vez mais a produção imediata, em detrimento de uma análise mais elaborada e de uma crítica mais profunda. O tipo ideal parece ser o pesquisador puro, como se as ciências da gestão se identificassem com a física teórica ou com a biologia molecular.

Ademais, promove-se a propagação do conhecimento explícito e desconsiderase a socialização, a disseminação do conhecimento tácito e a aprendizagem pelo exemplo. Serão, no futuro, negligenciados os espaços de discussão e de reflexão, como a sala de aula? O dedicado mestre, o excelente professor, o palestrante entusiasmado e o conselheiro paciente estarão todos em extinção? E serão eles substituídos por pesquisadores robotizados, verdadeiras máquinas de publicar? Se o futuro dos estudos de estratégia é promissor, o desafio é enorme e estimulante. 


\section{ReferênCias Bibliográficas}

Allouche, J., \&

Schmidt, G. (1995).

Les outils de la décision stratégique.

Paris: Éditions la Découverte.

Bignetti, L. P.,

Cappra, C. M., \&

Thomas, E. (2007, June).

La recherche dans le domaine de la stratégie au Brésil: bilan et défis à l'aube du XXI siècle. Table Ronde. Conférence Internationale de Management Stratégique, Montreal, Canada, 16.

Bignetti, L. P., \&

Paiva, E. L. (2002).

Ora (direis) ouvir estrelas: estudo das citações de autores de estratégia na produção acadêmica brasileira. Revista de Administração Contemporânea, 6(1), 105-125.

DiMaggio, P. J., \&

Powell, W. W. (1991).

Introduction. In W. W. Powell \& P. J. DiMaggio (Eds.). The new institucionalism in organizational analysis (pp. 1-38). Chicago: The University of Chicago Press.
Hafsi, T., \&

Toulouse, J. M. (1996).

La stratégie des organisations: une synthèse. Montréal: Les Éditions Transcontinental.

Martinet, A-C. (2001).

Épistémologie de la connaissance praticable: exigences et vertus de l'indiscipline. In A. David, A. Hatchuwel, \& Laufer, R. (Coords.). Les nouvelles fondations des sciences de gestion: élements d'épistémologie de la recherche en management. Paris: FNEGE.

Tolbert, P. S., \& Zucker, L. G. (1999).

A institucionalização da teoria institucional. In S. R.Clegg, C. Hardy, \& W. R. Nord (Eds.). Handbook de estudos organizacionais (Vol. 1, pp. 196-219). São Paulo: Atlas.

Zucker, L. (1987).

Institutional theories of organization. Annual Review of Sociology, 13(1), 443-464. 
